\title{
OPTIMIZING METHODS TO MEASURE HYDRODYNAMICS IN COASTAL WETLANDS: EVALUATING THE USE AND POSITIONING OF ADV, ADCP AND HR-ADCP
}

\author{
E.M. Horstman', T. Balke², T.J. Bouma ${ }^{2,3}$, C.M. Dohmen-Janssen', S.J.M.H. Hulscher ${ }^{1}$ \\ Hydrodynamic impacts of vegetation in the intertidal zone are highly important to coastal protection. However, most \\ studies on hydrodynamic impacts of vegetation in the intertidal zone are carried out in flumes. This results in a lack of \\ field data for validating models that describe short-term hydrodynamic impacts of vegetation. The current research focuses \\ on field measurements of flow patterns and waves in vegetated intertidal areas. Ample measurement devices are available \\ to measure hydrodynamic processes in the field. Examples are: acoustic Doppler current profilers (ADCP), high resolution \\ acoustic Doppler current profilers (HR-ADCP) and acoustic Doppler velocity meters (ADV). This study focuses on the \\ differences in the performance of these devices, to determine which of them can be best deployed in a future fieldwork \\ campaign in mangroves. Major points of attention in this comparison are the accuracy of the data and the potential \\ disturbance of the measurements by the presence of vegetation. It is concluded that ADV's perform very well in vegetated \\ intertidal areas, while (HR-)ADCP's show difficulties when deployed upward looking. Furthermore, ADV's are preferred \\ over (HR-)ADCP's due to their ability of combining high frequent wave and current measurements and their convenient \\ deployment.
}

Keywords: salt marsh; mangrove; hydrodynamics; field measurements; acoustic Doppler instruments

\section{INTRODUCTION}

The intertidal part of the coastal zone is regularly exposed to hydrodynamic forces of the sea. In those intertidal areas where the hydrodynamic forces are limited (e.g. in estuaries, lagoons and other sheltered parts of the coast) the interface between land and sea forms the habitat of a very precious ecosystem: the coastal wetland (Reed 2005). Three types of coastal wetlands exist: mangroves, salt marshes and tidal freshwater marshes (Mitsch and Gosselink 2007). This paper focuses on the saline coastal wetlands that are vegetated by halophytes (i.e. salt tolerant species): salt marshes and mangroves.

Vegetation in salt marshes and mangroves interferes with hydrodynamics and morphodynamics. A difference can be made between the restrictions that hydrodynamics and morphology impose on the establishment of a vegetation cover at one hand and the impact of vegetation on hydrodynamics and morphodynamics (and thus morphology) on the other hand. The latter interplay, vegetation affecting physical processes, is facing increased attention by coastal engineers as the presence of coastal vegetation can lead to increased safety of the hinterland against flooding (Barbier et al. 2008). Increasing effort is being undertaken to model the use of salt marshes and mangroves for attenuation of hydrodynamic forces and sediment accretion (Bouma et al. 2007; Temmerman et al. 2005; VoLuong and Massel 2008; Wolanski et al. 2002). For salt marshes these modeling attempts are often validated against field and flume data (Bouma et al. 2007; Temmerman et al. 2005). For mangroves it is found that available field data are limited (either in time span, spatial coverage or the range of natural conditions taken into account) (Massel et al. 1999; Teh et al. 2009) and physical modeling efforts are sparse and highly simplified (Struve et al. 2003). Profoundly calibrated and validated models for mangroves are lacking due to this reason.

Field data are highly valuable to increase knowledge on the use of vegetation for coastal protection. These field data should cover sufficient temporal and spatial scales in order to understand the hydrodynamics of salt marshes and mangroves under all conditions occurring during the different seasons of the year (even extreme conditions if possible) and for different field lay-outs. The first problem we meet in this process is monitoring the short-term hydrodynamics (i.e. waves and currents) in a coastal wetland. Previous field studies apply a variety of devices: marked stakes (visual), (differential) pressure sensors and acoustic surface tracking to record waves (Brinkman 2006; Hong

1 University of Twente, Department of Water Engineering \& Management, PO Box 217, 7500 AE Enschede, The Netherlands

2 Deltares, Marine \& Coastal Systems, PO Box 177, 2600 MH Delft, The Netherlands

${ }^{3}$ Netherlands Institute of Ecology, Centre for Estuarine and Marine Ecology, PO Box 140, 4400 AC Yerseke, The Netherlands 
Phuoc and Massel 2006; Möller et al. 1999; Pedersen and Nylund 2006; Quartel et al. 2007; Yang 1998) and rotor/vane current meters, micro current meters from plankton nets (video tracking), electromagnetic current meters and acoustic Doppler velocimeters to record currents (Bouma et al. 2005; De Boer et al. 2000; Furukawa et al. 1997; Mazda et al. 1997; Neumeier and Amos 2006; Quartel et al. 2007). A thorough comparison of the performance of these devices, other than a qualitative comparison, is hardly available however (Gordon and Lohrmann 2001; Koch et al. 2006; Schretlen and Van der Werf 2006). Moreover, some new devices have been developed during the recent years that have only been sparsely used yet for data retrieval in the intertidal zone. This paper aims to compare the performance of three state-of-the-art acoustic Doppler velocimetry devices through a range of test measurements in a salt marsh in the Netherlands.

This paper starts with an introduction comparing vegetated intertidal areas at different latitudes and a description of the field site. Subsequently, the hydrodynamic equipment and the set-up of the field measurements are introduced. After a brief explanation on the retrieval and processing of data from the deployed equipment, the resulting findings on currents and waves in a salt marsh are presented. While looking after the physical meaning of these findings, the data retrieved by the different devices will also be compared, resulting in a final comparison of these acoustic instruments in the discussion. The paper concludes with some findings on the hydrodynamics in salt marshes and with the recommendations following from the outcomes of the comparison of the acoustic instruments.

\section{STUDY AREA: SALT MARSH VS. MANGROVE}

Vegetated saline coastal wetlands are inhabited by either salt marsh species or mangroves. So both salt marshes and mangroves face the same forcing by incoming tides and waves. Salt marshes consist of shrubs and herbaceous plants, mainly grasses, and are often limited to the temperate climatic zones (Healy 2005). Mangroves consist of shrubs and trees and occur in the tropics and subtropics (Bird 2005). Salt marshes and mangroves can occur together in warm temperate areas, the subtropics and sometimes even in the tropics but in case of this coexistence both vegetation types occupy different levels in the intertidal zone (Healy 2005). Their special roots enable a number of mangroves to grow on completely water-logged soils at lower elevations than salt marsh grasses are able to (Augustinus 1995).

As salt marshes and mangroves occur in similar sheltered coastal habitats, they also face similar hydrodynamic forcing by waves and tidal currents. Observed average wave heights in the pioneer zone of salt marshes range up to $0.2 \mathrm{~m}$ (Roland and Douglass 2005), with significant wave heights ranging up to about 0.2-0.5 m (Möller et al. 1999). Significant wave heights in mangroves are reported to go up to 0.2-0.25 m (Anthony 2004; Brinkman 2006; Hong Phuoc and Massel 2006). Observed maximum tidal flow velocities in salt marshes are about $0.2-0.3 \mathrm{~m} / \mathrm{s}$, while for mangroves velocities of 0.2-0.5 m/s have been reported (Anthony 2004; Bouma et al. 2005; Hong Phuoc and Massel 2006). So in general one could say that both systems face significant wave heights of several decimeters and maximum tidal flow velocities of the order of decimeters per second.

As mangroves and salt marshes show a rather good hydrodynamic resemblance, this study has only been conducted in the pioneer zone of the Zuidgors salt marsh in the Netherlands. This salt marsh is located in the Western Scheldt estuary (figure 1). The marsh is backed by a dike and consists of a densely vegetated plateau of up to $250 \mathrm{~m}$ wide (figure 2). A cliff of several 10's of centimeters separates the seaward edge of the plateau from the pioneer zone, which is a sparsely vegetated mudflat with an average width of about $400 \mathrm{~m}$ (Van der Wal et al. 2008). Vegetation in the pioneer zone consists of Spartina anglica tussocks, while the plateau shows a more diverse vegetation cover also containing Puccinellia maritima, Suaeda maritima and Aster tripolium (Van der Wal et al. 2008). The Western Scheldt is exposed to a semi-diurnal tide. Amongst the many salt marshes along the Western Scheldt, Zuidgors faces the highest frequency of moderate waves and highest current velocities, causing a net vegetation loss. Retreat of the cliff has lead to an increase of the mudflat elevation (Van der Wal et al. 2008).

Measurements described in this paper are conducted in the pioneer zone of the Zuidgors salt marsh. Although natural vegetation is present, artificial vegetation has been applied as to be able to control vegetation characteristics (i.e. density and height). Vegetation has been mimicked by planting $1 \mathrm{~m}^{2}$ patches of bamboo poles with an above ground height of approximately $50 \mathrm{~cm}$ and a diameter of 
about $1 \mathrm{~cm}$. The configuration of these poles and their attributes are a mixture between densities, height and stiffness of both salt marsh grasses and mangrove roots. To study the impact of vegetation on the data collection by the applied devices (see next section), bamboo densities have been varied between 0,100 and 200 stems per squared meter.

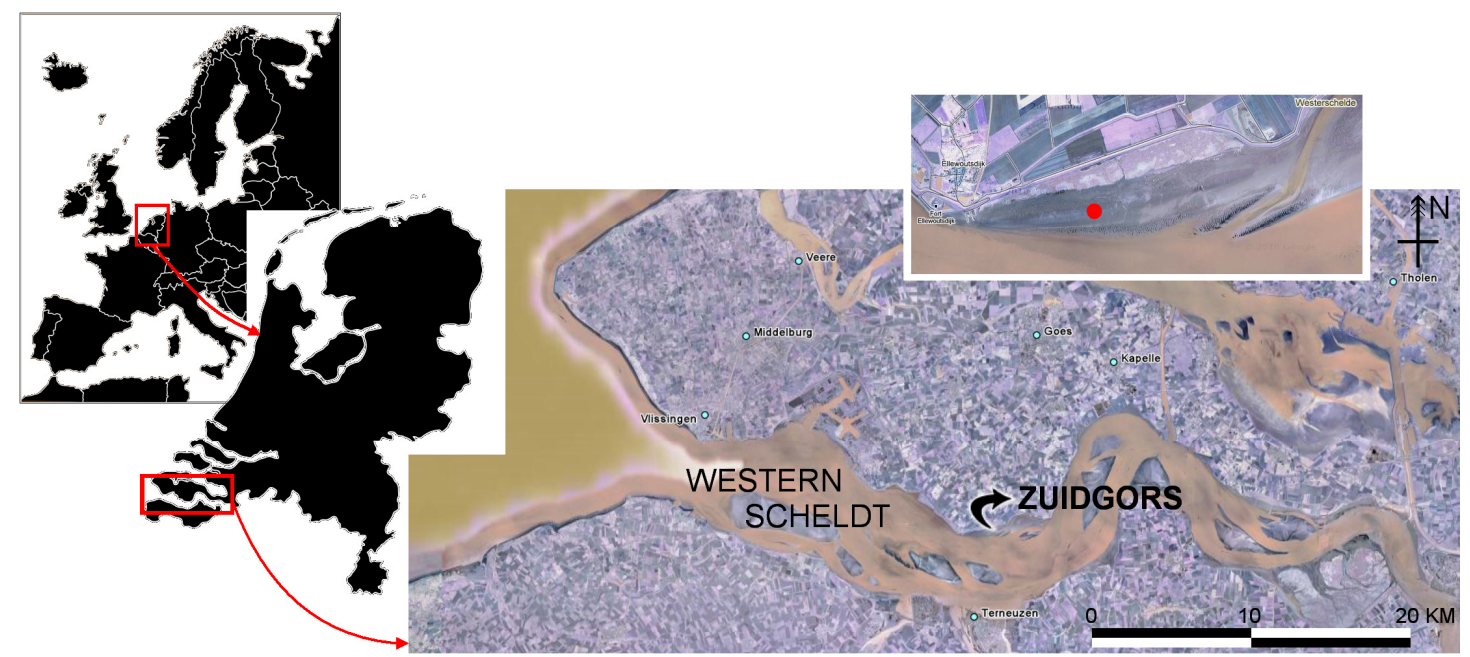

Figure 1. The field site for this study is the Zuidgors salt marsh, located in the Western Scheldt estuary in the Netherlands. The inset shows a close-up of the Zuidgors and the red dot indicates the location of the study area.

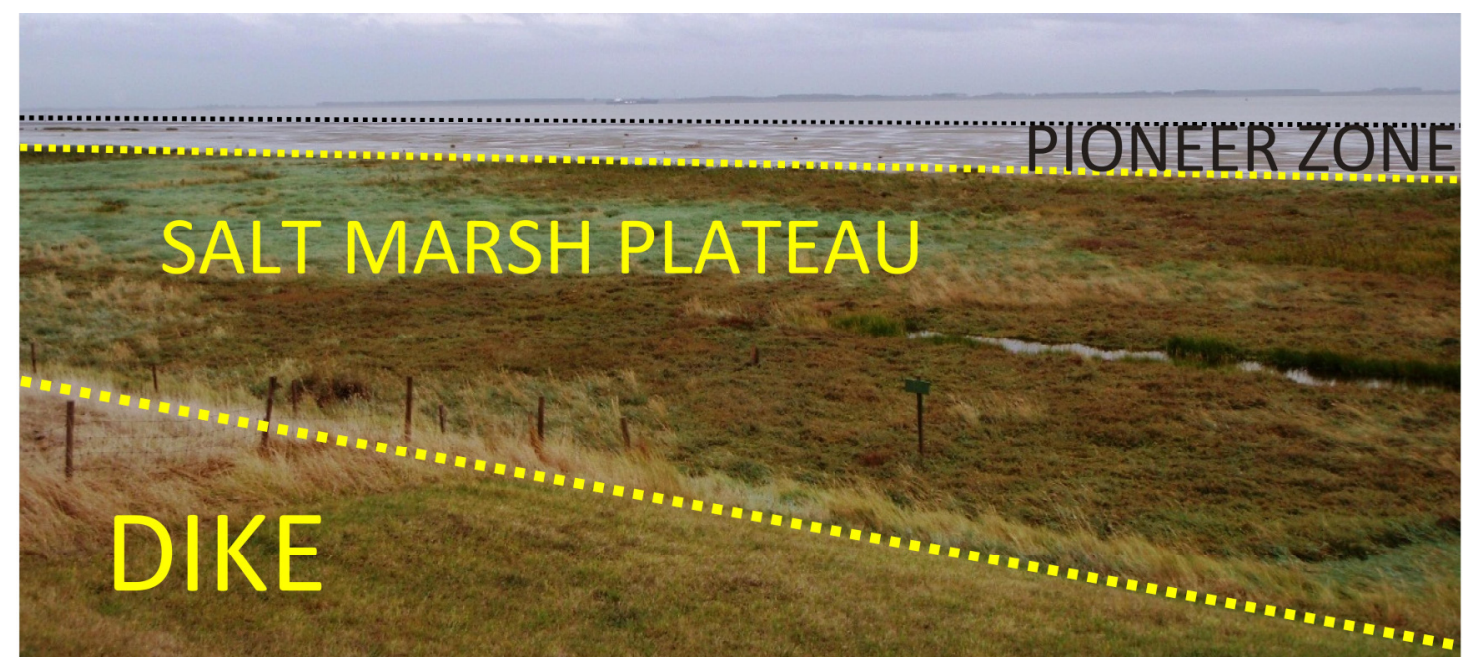

Figure 2. The Zuidgors salt marsh is backed by a dike in front of which the higher elevated salt marsh plateau starts. The pioneer zone has characteristically a lower elevation, is sparsely vegetated and is separated from the plateau by a cliff.

\section{ACOUSTIC DEVICES FOR MEASURING SHORT-TERM HYDRODYNAMICS}

Previous comparisons have shown that the new generation acoustic instruments have better capabilities for monitoring hydrodynamics than their mechanical, optic and electromagnetic predecessors (Garcia et al. 2005; Kraus et al. 1994; Lane et al. 1998; Lohrmann et al. 1994; Terray et al. 1999). Mechanical flow tracking is sensitive to aging of components while exposed to field conditions. Use of laser Doppler velocimetry (LDV) or particle image velocimetry (PIV) is rather infeasible in large scale measurements and might also face problems in sediment rich environments (Garcia et al. 2005). A major drawback for electromagnetic flow meters (EMF) is that they only measure flow velocities in two directions (Schretlen and Van der Werf 2006), which is insufficient for monitoring total kinetic energy (TKE, i.e. turbulence). Next to that, technologies for measuring both directional waves and currents are traditionally separated (Terray et al. 1999); both (an array of) pressure sensors and velocimeters were needed. Acoustic Doppler devices combine these 
measurements through an integrated pressure sensor and tree dimensional acoustic Doppler flow tracking. This results in both PUV data (pressure and both horizontal velocity components) for deriving wave spectra (Gordon and Lohrmann 2001) and in three-dimensional current velocity data (Terray et al. 1999).

For this study three different acoustic Doppler instruments have been deployed: a $2.0 \mathrm{MHz}$ Nortek High-Resolution Acoustic Doppler Current Profiler (HR-ADCP), a 2.0 MHz Nortek Acoustic Doppler Current Profiler (ADCP) and two 6.0 MHz Nortek Acoustic Doppler Velocimeters (ADV's) with cable probes. These instruments' measurements are all based on the Doppler shift in reflected sound pulses. Sound pulses are being emitted in narrow beams. Reflection of these pulses at moving particles in the water column (e.g. suspended sediments or plankton) causes a change in the frequency of the echo of the pulses. This echo is being detected again by the instrument and the observed change in the frequency is being translated into a flow velocity along each beam, assuming that the water movement equals the mobility of the dissolved particles (Lohrmann et al. 1994). The presence of either one transmitter and three receivers (for ADV's) or three combined transmitters and receivers (for (HR-) ADCP's) facilitates the monitoring of 3D velocities through geometrical analysis of the results for each of the three echoes (Lohrmann et al. 1994; Nortek AS 2005a; Nortek AS 2005b).

The difference between the ADV, ADCP and HR-ADCP is in the data coverage. ADV's measure velocities in three directions in one point only, being located $15.7 \mathrm{~cm}$ above the transmitter head. The sampling volume for this point measurement is $14 \mathrm{~mm}$ in diameter and $14 \mathrm{~mm}$ in height (Nortek AS 2005b). The ADCP reports three dimensional flow velocities in a user selectable number of cells (i.e. layers) within the water column. For a $2.0 \mathrm{MHz} \mathrm{ADCP}$, the maximum profiling range goes up to 8.0 $\mathrm{m}$, cell sizes can be as small as $0.1 \mathrm{~m}$ (with a maximum of 128 cells) and the minimum blanking distance over the transmitter/receiver head is $0.05 \mathrm{~m}$ (Nortek AS 2005a). For the HR-ADCP, maximum profile range is only $3.0 \mathrm{~m}$, but cell sizes can get as small as $0.01 \mathrm{~m}$ and the minimum blanking distance goes down to $0.03 \mathrm{~m}$ (derived from the HR-ADCP software). Next to that, all these devices contain a compass and tilt, temperature and pressure sensors in the end bell of their canisters. Except for the pressure sensor data, these measurements are not considered in this paper.
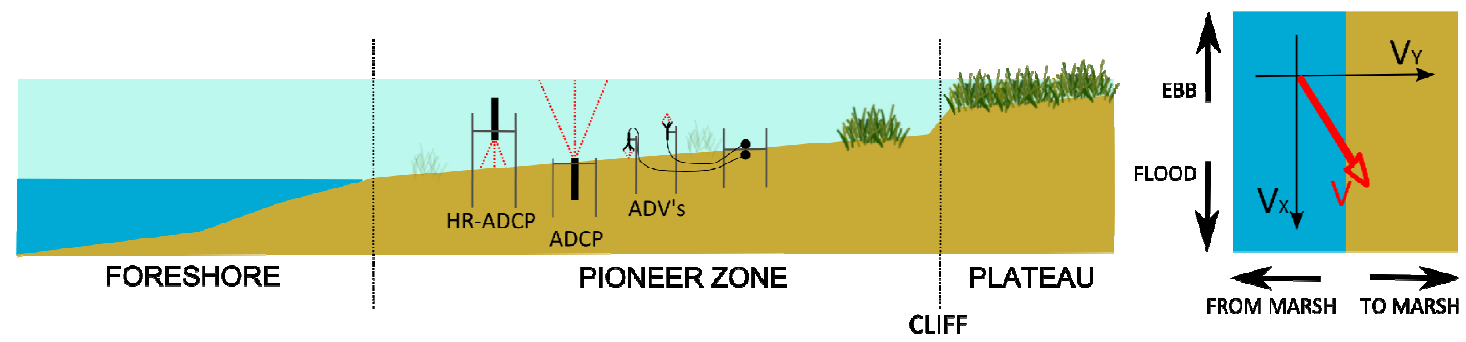

Figure 3. Schematic field set-up on the Zuidgors salt marsh. HR-ADCP, ADCP and (cable probe) ADV's are placed at different heights along a cross-shore transect through the pioneer zone. The equipment has been secured to metal structures to prevent drifting. The top view at the right indicates the major flow directions at the study site and the positioning of the axes of the velocity measurements conducted.

\section{RETRIEVING AND PROCESSING FIELD DATA}

Figure 3 shows the field set up of the different acoustic devices that have been deployed. The cable probe ADV's have been mounted to obtain velocity data at $0.05 \mathrm{~m}$ (downward looking) and 0.50 $\mathrm{m}$ (upward looking) above the bed. Sampling rates of both ADV's are set at $8 \mathrm{~Hz}$, with a burst interval of $90 \mathrm{~s}$ and 200 samples being taken per burst (so data were collected over the first $25 \mathrm{~s}$ of every burst). The ADCP has been buried so that the head was only slightly elevated from the surrounding bottom to prevent sediment accumulation on top of it. With a burst interval of $180 \mathrm{~s}$ and an averaging interval of $60 \mathrm{~s}$ velocities were monitored for 20 cells of $0.10 \mathrm{~m}$ height with a blanking distance of $0.20 \mathrm{~m}$. The HR-ADCP has been deployed downward looking from a height of $0.50 \mathrm{~m}$ above the bed. Data were collected every $180 \mathrm{~s}$ and averaged over the first $60 \mathrm{~s}$ of this interval for 10 cells of $0.05 \mathrm{~m}$ with $0.05 \mathrm{~m}$ blanking distance. All instruments have also been monitoring water pressure at the same frequencies/intervals. Since pressure sensors are located in the end bell of the canisters however, the basic elevations of these data are different from the ones of the velocity data. All equipment has been 
secured to anchored metal structures to prevent drifting of the sensors, which would affect the velocity data (especially directions).

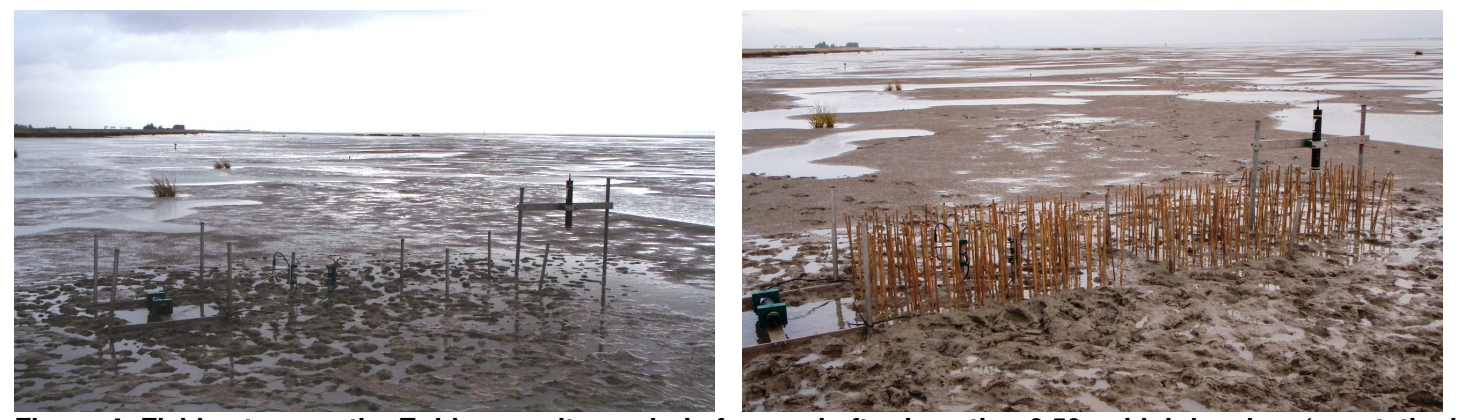

Figure 4. Field set-up on the Zuidgors salt marsh, before and after inserting $0.50 \mathrm{~m}$ high bamboo 'vegetation' $\left(100 \mathrm{stems} / \mathrm{m}^{2}\right)$ within the measurement study area.

The field set-up has been deployed for a period of 8 days, from October $5^{\text {th }}$ to October $13^{\text {th }} 2009$. Measurements have subsequently been executed for a bare mudflat (4 tidal cycles), a $100 \mathrm{stems} / \mathrm{m}^{2}$ bamboo cover ( 2 tides), a 200 stems $/ \mathrm{m}^{2}$ bamboo cover (4 tides), a $100 \mathrm{stems} / \mathrm{m}^{2}$ bamboo cover $(2$ tides) and again a bare mudflat (4 tides). Figure 4 shows this set-up in the field, both with and without the bamboo 'vegetation'. In the midst of this measurement period, the deployment of the HR-ADCP has been changed into upward looking from the bottom level, equal to the ADCP.

The raw velocity data provided by the acoustic instruments had to be filtered. The ADV output couples a noise correlation factor to each velocity measurement. As low correlation is an indicator for noisy data of low quality, measurements with a correlation lower than $70 \%$ are discarded (SonTek 1997). The (HR-)ADCP gives an amplitude of the received signal with every velocity measurement. This amplitude represents the strength of the received acoustic signal. The noise floor for this signal is 30 counts (i.e. approximately $12 \mathrm{~dB}$ ), below this signal strength the related data are unreliable and cannot be used (Nortek AS 2005a). Moreover, it is found that this noise floor has to be increased to 150 counts in case of the upward looking ADCP to exclude signal reflections at and above the water surface. This was found out as the ADCP is measuring up to $2.20 \mathrm{~m}$ above the bed level. Due to the tides, the field site is not permanently flooded this deep, but velocity data with an amplitude of even more than 100 counts have been detected above the instantly monitored water level. An increased noise floor of 150 counts removed the majority of these peculiarities while leaving the real data for the water column rather unaffected.

After filtering the collected data sets for noise, the ADCP velocity data still turned out to be rather inaccurate since velocity profiles were showing a disturbed pattern in stead of a smooth line. To reduce this scattering velocity data were averaged over five averaging intervals of $60 \mathrm{~s}$ each, increasing the averaging time to $300 \mathrm{~s}$ with a total measurement interval time of $900 \mathrm{~s}$. Neither the increased noise floor nor the additional averaging was needed for the HR-ADCP data.

\section{CURRENTS AND WAVES IN A TIDAL MARSH}

\section{Currents}

Measurements of water levels and current velocities have been undertaken over a period of 8 days, so tidal forcing changed throughout this campaign as it covered half of a spring-neap tidal cycle. Water level elevation over the study area has been monitored by all instruments and gave similar results. However, due to the mounting height the blanking distance for water depth measurements was different. Figure 5 shows the water depth data retrieved from the pressure sensors in the downward looking mounted ADV. 


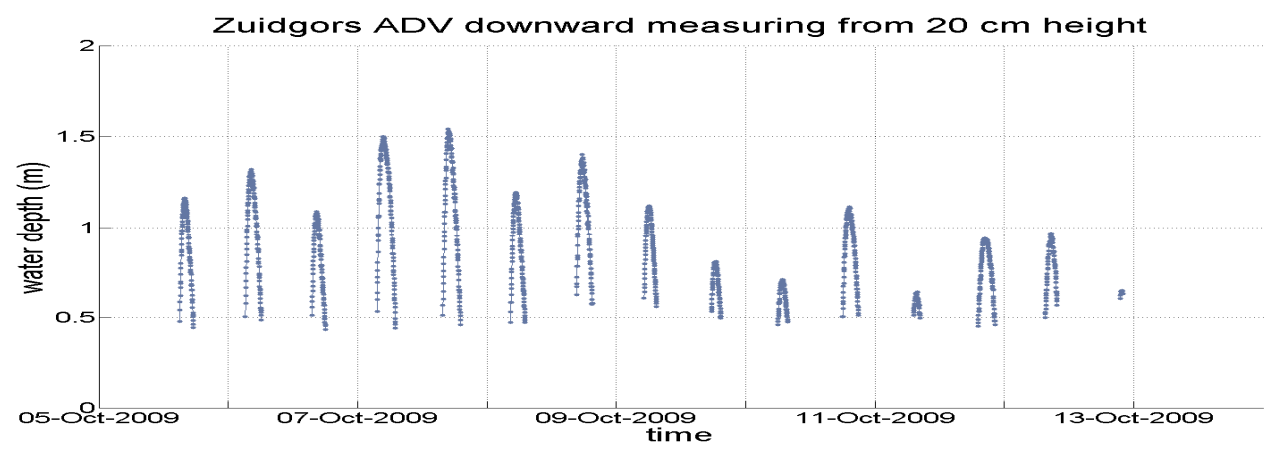

Figure 5. Tidal inundation of the Zuidgors as measured by the pressure sensor in one of the ADV's.

Current velocities have been monitored parallel and perpendicular to the edge of the mudflat and along the vertical. Parallel (x) and perpendicular (y) velocity components turned out to be of similar magnitude. In figure 3 it is shown how resulting horizontal velocities are derived. Positive resulting horizontal velocities are connected to incoming tides and negative values to outgoing tides. Resulting horizontal flow velocity data retrieved from the ADV's are plotted in figure 6 for all stages of the tidal cycle and for several vegetation densities. Figure 6 gives a good indication of the accuracy of the ADV data as the velocity data for each tide show minor noise around the plotted graphs. The curves in figure 6 clearly show that with increasing water depths over the mudflat the maximum current velocities are increasing as well and that higher current velocities are found at a higher elevation over the mudflat (since the impact of friction is reduced). The results also show higher maximum current velocities during incoming tides than for outgoing tides and the plots are slightly skewed towards the positive flow velocities. This finding is in accordance with previous studies on salt marsh hydrodynamics (Bouma et al. 2005). These peculiarities can be attributed to the tidal asymmetry caused by the salt marsh plateau backing the mudflat. With incoming tide, the dense vegetation opposes the tidal inflow and current velocities increase rather slowly until the vegetation is submerged. When the tide turns however, the vegetation tends to retain the water. This causes a negative water level gradient towards the edge of the mudflat when the water level in the estuary is falling, resulting in current velocities that increase while the water level is decreasing already. These phenomena are a common feature of salt marshes and mangroves (Bouma et al. 2005; Mazda et al. 1995).

It is not possible to derive from these data the impact of the mimicked vegetation on the current velocities as different densities have been mimicked during different tides. The change in tidal forcing over time makes it impossible to isolate the impact of increased vegetation density on the current velocities. Figure 6 for example shows higher maximum flow velocities for a bamboo density of 200 poles $/ \mathrm{m}^{2}$ than for 100 poles $/ \mathrm{m}^{2}$ on the $8^{\text {th }}$ of October. Nonetheless, figure 6 shows that the accuracy of the ADV data is good as the velocity data for each tide show minor noise (about $10 \%$ scatter) around the plotted graphs. Also there is no significant increase of the data scatter in case of vegetation compared to a case without vegetation.
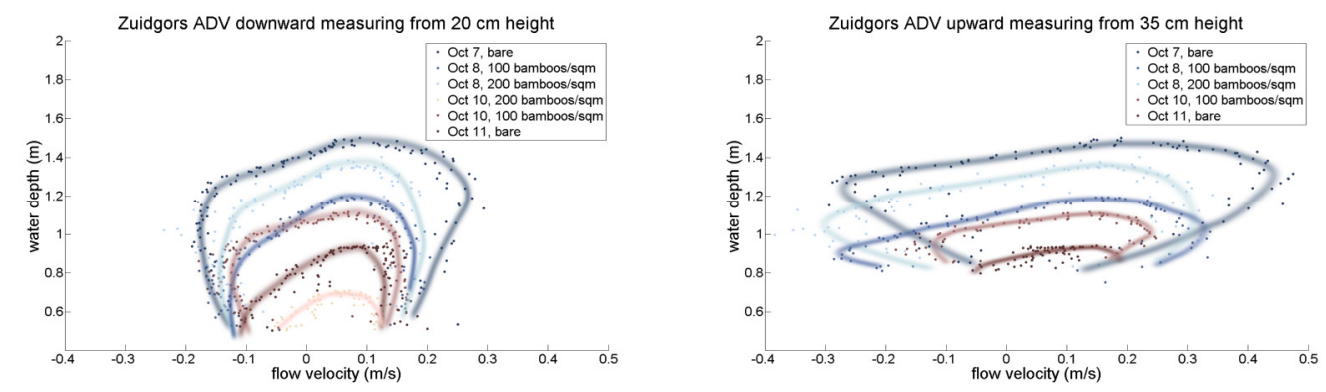

Figure 6. Development of current velocities over the tidal cycle at $5 \mathrm{~cm}$ (left) and $50 \mathrm{~cm}$ (right) above the bed of the mudflat. Different colors show results for different vegetation characteristics that have been mimicked. Positive velocities represent incoming tides. 


\section{Waves}

The high frequency $(8 \mathrm{~Hz})$ pressure data of the ADV's are used to analyze wave data for the Zuidgors salt marsh. For each burst of $25 \mathrm{~s}$ average wave heights have been calculated after subtraction of the tidal elevation from the pressure data and the subsequent calculation of the maximum amplitudes between the zero-crossings of the resulting wave signal (figure 7). Calculated wave heights range from several centimeters up to about $13 \mathrm{~cm}$ only and wave periods vary from several seconds up to 7 seconds. These waves are slightly lower than the $15 \mathrm{~cm}$ average wave height that Van der Wal et al. estimated for this area by applying an USACE model (Van der Wal et al. 2008).

One interesting phenomenon is that the wave height seems to increase over the tidal cycle. Figure 8 shows that observed wave heights are generally higher for the same water levels during ebb tide than during flood tide. The presence of this trend over all tides indicates that it cannot be caused by (random) changes in heights of incoming waves. The increase of wave heights during ebb tides is directly linked to the tides itself through current induced shoaling. In case of incoming tide, current velocities are directed onshore and into the estuary (see figure 3). Waves propagate in the same direction and transfer energy to the current, making them decrease in height (Van Rijn 2008). On the opposite, during ebb tide the current is directed offshore and towards the mouth of the estuary. The waves still propagate in the same direction and gain energy from the opposing current now, causing them to increase in height (Van Rijn 2008). This energy transfer between waves and currents has not been found to be included in hydrodynamic field studies of salt marshes (or mangroves) yet as they focus on either waves or currents alone and not on total hydrodynamic energy (Bouma et al. 2005; Brinkman 2006; Hong Phuoc and Massel 2006; Möller et al. 1999; Quartel et al. 2007). As waves transfer energy to currents and vice versa it might be useful to study attenuation of total hydrodynamic energy in these types of vegetation instead.
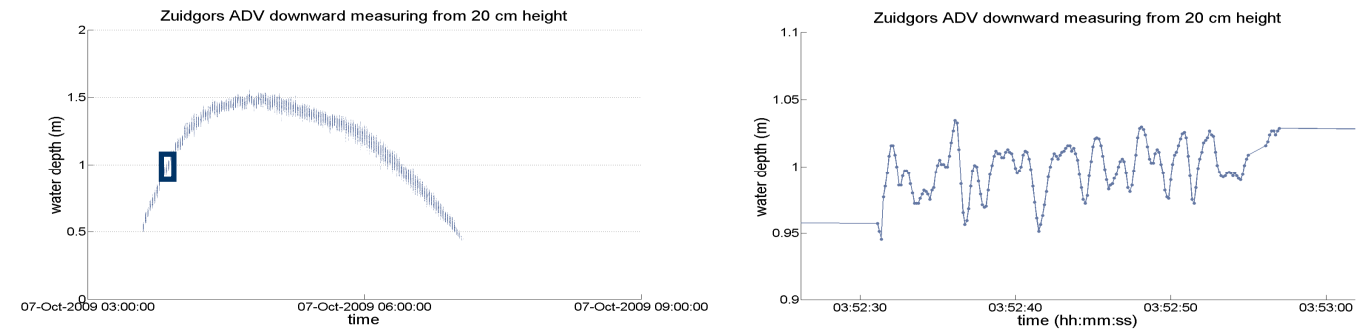

Figure 7. The ADV's are retrieving data at an $8 \mathrm{~Hz}$ frequency (left), resulting in a detailed wave signal for every burst of $25 \mathrm{~s}$ (right). The tidal signal (average water level per burst) has been subtracted from the wave signal for further analysis of the waves.
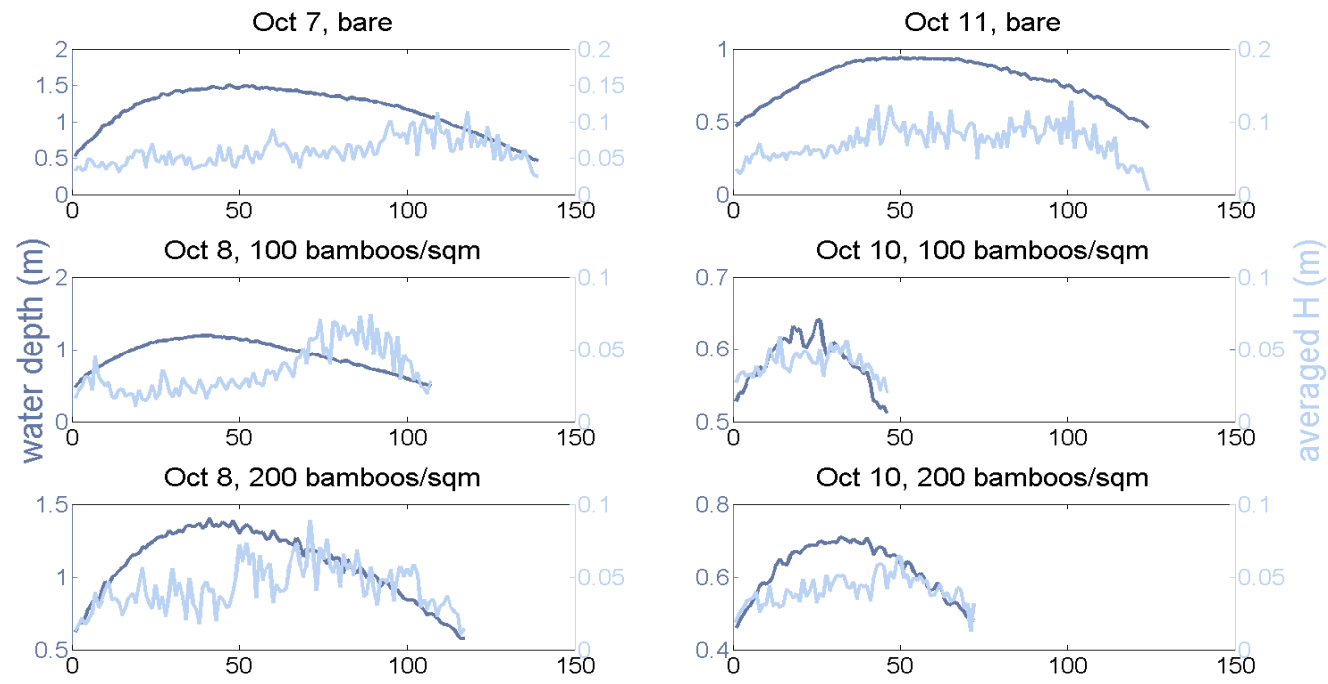

Figure 8. Average wave heights and tidal amplitudes per burst for 6 tidal cycles with three different vegetation densities. 


\section{DISCUSSION: COMPARISON OF ACOUSTIC INSTRUMENTS}

To compare the performance of ADV's, ADCP and HR-ADCP, velocities measured by all devices are shown in the same plots in figure 9. As has been stated before, all data are filtered to remove noise. ADCP data have additionally been averaged to smoothen velocity profiles and the noise filter for these data has been increased to remove 'unrealistic' data above the water level. In case of the measurements without bamboos (upper panel in figure 9) velocities measured by the different devices agree rather well and the velocity profiles look realistic (except for one outlier for the ADV data). However, the data from the upward looking ADCP still show spikes in the flow velocity profiles.
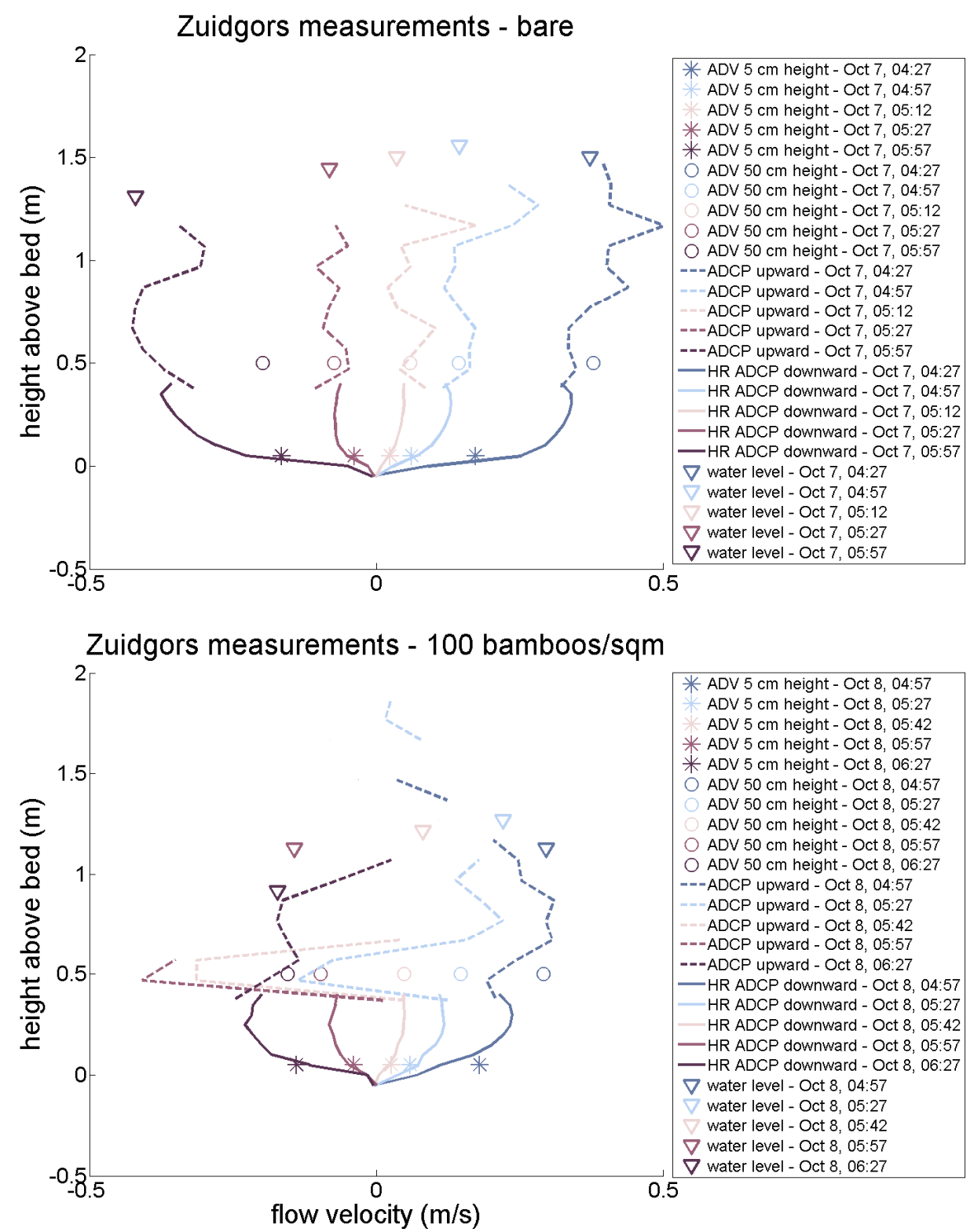

Figure 9. Flow velocity data as measured by all deployed equipment for 0 and 100 bamboos $/ \mathrm{m}^{2}$ densities. Each color shows velocity data for one of five points in time during a tidal cycle. Water levels are indicated by triangles to show where velocity profiles should stop.

After putting the bamboos in (lower panel in figure 9), data for the ADV's and the downward looking HR-ADCP are still of a good quality and in accordance. The ADCP data however shows some strange spikes at the height of the top of the bamboo vegetation (i.e. $50 \mathrm{~cm}$ height) and despite the 
very high noise level the ADCP data still show results above the water level. The latter issue can be solved by increasing the noise level even further (at the cost of loosing data within the water column as well though). An explanation for the spikes in the ADCP data has not been found. Although they occurred in all measurements with bamboo vegetation, it is impossible that the flow velocity over the bamboos increases that much and is always directed in the same direction (as occurred in the data). These features are also not indicated by the ADV data that are available for the same height.

Results from the second half of the measurement campaign, when the HR-ADCP was also deployed upward looking, indicate that HR-ADCP measurements suffer from the same problems as the ADCP, i.e. for an upward looking HR-ADCP velocity measurements become much less accurate as well and velocity peaks are being measured at the top of the bamboo layer. These performance issues with (HR-) ADCP's when deployed upward looking might be related to difficulties in coping with varying water levels (a fixed water level has to be set before deployment) and any gradients at the top of the vegetation canopy.

To use the pressure sensors of the deployed equipment for monitoring waves, monitoring frequencies of the (HR-)ADCP need to be increased. Data have now been averaged over bursts of 60 seconds but to be able to analyze wave characteristics a minimum frequency of about $2-5 \mathrm{~Hz}$ is needed. This would require extensive battery and data recorder capacities. The resulting data files will be very large and inconvenient to work with. The ADCP has a special wave setting overcoming this problem to a certain extent.

\section{CONCLUSIONS AND RECOMMENDATIONS}

As new generation acoustic instruments appear to have better capabilities for monitoring hydrodynamics than their mechanical, optic and electromagnetic predecessors, this study compares the performance of three acoustic instruments (ADV, ADCP and HR-ADCP). This comparison is based on a short field survey in the Zuidgors salt marsh in the Netherlands. Retrieved current velocity data resemble established phenomena in (salt marsh) hydrodynamics like increased velocities at higher water levels and delayed discharge at ebb tides.

Moreover, analysis of the wave data (from the pressure sensors in the ADV) showed the presence of current induced shoaling, giving rise to increased wave heights at outgoing tide. Yet, this energy transfer between waves and currents has often been neglected. Studies into the impact of salt marshes or mangroves on coastal protection focus on either the reduction of wave energy or the reduction of current velocities. However, when waves transfer energy to the tidal currents with incoming tide for example, it might be worthwhile to include hydrodynamic energy contained by the current in these studies.

Concerning the performance of the deployed acoustic devices, velocity measurements by acoustic Doppler velocimeters and (high resolution) acoustic Doppler current profilers are accurate (i.e. little noise) and correspond well with one another. However, it is found that in the intertidal area the profilers give less accurate results if deployed upward looking. There also seems to be interference between vegetation and these profilers creating unexplainable peaks in the velocity data collected. These problems can be overcome by deploying the profilers downward looking.

The main advantage of ADV's is the potential to combine velocity and wave measurements, which is much more complex with (HR-)ADCP's. The inherent disadvantage of ADV's however is that they only measure point data, while profilers measure full current profiles for the entire water depth. It depends on the information needed whether the point data of the ADV are sufficient. By deploying several ADV's one could still derive current profiles with ADV's. Once the general shape of the current profiles is known point data might suffice as related velocity profiles could be estimated.

Another advantage of the deployed cable probe ADV's is their convenient design which makes it easy to fix them in harsh intertidal environments. The probes can easily be fixed to a pole while the canisters (for batteries and memory) can be fixed to any stable structure (e.g. a tree). For (HR-) ADCP's, that have an integrated canister and probe, much stiffer constructions are required to mount them properly, especially in case of downward looking deployment. 


\section{ACKNOWLEDGMENTS}

This research is funded by the Singapore-Delft Water Alliance (SDWA). We are grateful to the Netherlands Institute of Ecology (NIOO-KNAW) for making available the field equipment and for their assistance in the fieldwork.

\section{REFERENCES}

Anthony, E.J. 2004. Sediment dynamics and morphological stability of estuarine mangrove swamps in Sherbro Bay, West Africa. Marine Geology, 208(2-4), 207-224.

Augustinus, P.G.E.F. 1995. Geomorphology and sedimentology of mangroves. In: G.M.E. Perillo (Editor), Developments in Sedimentology. Elsevier, pp. 333-357.

Barbier, E.B., E.W. Koch, B.R. Silliman, S.D. Hacker, E. Wolanski, J. Primavera, E.F. Granek, S. Polasky, S. Aswani, L.A. Cramer, D.M. Stoms, C.J. Kennedy, D. Bael, C.V. Kappel, G.M.E. Perillo and D.J. Reed. 2008. Coastal ecosystem-based management with nonlinear ecological functions and values. Science, 319(5861), 321-323.

Bird, E. 2005. Mangroves, Geomorphology. In: M. Schwartz (Editor), Encyclopedia of Coastal Science. Springer, Amsterdam, pp. 611-613.

Bouma, T.J., M.B. De Vries, E. Low, L. Kusters, P.M.J. Herman, I.C. Tanczos, S. Temmerman, A. Hesselink, P. Meire and S. van Regenmortel. 2005. Flow hydrodynamics on a mudflat and in salt marsh vegetation: identifying general relationships for habitat characterisations. Hydrobiologia, 540, 259-274.

Bouma, T.J., L.A. van Duren, S. Temmerman, T. Claverie, A. Blanco-Garcia, T. Ysebaert and P.M.J. Herman. 2007. Spatial flow and sedimentation patterns within patches of epibenthic structures: Combining field, flume and modelling experiments. Continental Shelf Research, 27, 1020-1045.

Brinkman, R.M. 2006. Wave attenuation in mangrove forests: an investigation through field and theoretical studies. PhD Thesis, James Cook University, Townsville, 146 pp.

De Boer, W.F., L. Rydberg and V. Saide. 2000. Tides, tidal currents and their effects on the intertidal ecosystem of the southern bay, Inhaca Island, Mozambique. Hydrobiologia, 428(1-3), 187 196.

Furukawa, K., E. Wolanski and H. Mueller. 1997. Currents and sediment transport in mangrove forests. Estuarine Coastal and Shelf Science, 44(3), 301-310.

Garcia, C.M., M.I. Cantero, Y. Nino and M.H. Garcia. 2005. Turbulence measurements with acoustic Doppler velocimeters. Journal of Hydraulic Engineering, 131(12), 1062-1073.

Gordon, L. and A. Lohrmann. 2001. Near-shore Doppler current meter wave spectra. Waves 2001, San Francisco, California, USA, pp. 33-43.

Healy, T.R. 2005. Salt marsh. In: M. Schwartz (Editor), Encyclopedia of Coastal Science. Springer, Amsterdam, pp. 819-820.

Hong Phuoc, V.L. and S.R. Massel. 2006. Experiments on wave motion and suspended sediment concentration at Nang Hai, Can Gio mangrove forest, Southern Vietnam. Oceanologia, 48(1), 23-40.

Koch, E.W., L.P. Sanford, S.-N. Chen, D.J. Schafer and J. McKee Smits. 2006. Waves in seagrass systems: review and technical recommendations, U.S. Army Corps of Engineers, Washington.

Kraus, N.C., A. Lohrmann and R. Cabrera. 1994. New acoustic meter for measuring 3D laboratory flows. Journal of Hydraulic Engineering, 120(3), 406-412.

Lane, S.N., P.M. Biron, K.F. Bradbrook, J.B. Butler, J.H. Chandler, M.D. Crowell, S.J. McLelland, K.S. Richards and A.G. Roy. 1998. Three-dimensional measurement of river channel flow processes using acoustic Doppler velocimetry. Earth Surface Processes and Landforms, 23(13), 1247-1267.

Lohrmann, A., R. Cabrera and N.C. Kraus. 1994. Acoustic-Doppler velocimeter (ADV) for laboratory use. Funcamentals and Advancements in Hydraulic Measurements and Experimentation, Buffalo, New York, pp. 351-365.

Massel, S.R., K. Furukawa and R.M. Brinkman. 1999. Surface wave propagation in mangrove forests. Fluid Dynamics Research, 24(4), 219-249. 
Mazda, Y., N. Kanazawa and E. Wolanski. 1995. Tidal asymmetry in mangrove creeks. Hydrobiologia, 295(1), 51-58.

Mazda, Y., E. Wolanski, B. King, A. Sase, D. Ohtsuka and M. Magi. 1997. Drag force due to vegetation in mangrove swamps. Mangroves and Salt Marshes, 1(3), 193-199.

Mitsch, W.J. and J.G. Gosselink. 2007. Wetlands. John Wiley \& Sons Inc., Hoboken, USA, 586 pp.

Möller, I., T. Spencer, J.R. French, D.J. Leggett and M. Dixon. 1999. Wave transformation over salt marshes: A field and numerical modelling study from North Norfolk, England. Estuarine, Coastal and Shelf Science, 49(3), 411-426.

Neumeier, U. and C.L. Amos. 2006. The influence of vegetation on turbulence and flow velocities in European salt-marshes. Sedimentology, 53(2), 259-277.

Nortek AS. 2005a. Aquadopp current profiler; user guide, Nortek AS, Rud, Norway.

Nortek AS. 2005b. Vector current meter; user manual, Nortek AS, Rud, Norway.

Pedersen, T. and S. Nylund. 2006. Wave height measurements using acoustic surface tracking. Environmental research, engineering and management, 1(35), 18-25.

Quartel, S., A. Kroon, P. Augustinus, P. Van Santen and N.H. Tri. 2007. Wave attenuation in coastal mangroves in the Red River Delta, Vietnam. Journal of Asian Earth Sciences, 29(4), 576584.

Reed, D.J. 2005. Wetlands. In: M. Schwartz (Editor), Encyclopedia of Coastal Science. Springer, Amsterdam, pp. 819-820.

Roland, R.M. and S.L. Douglass. 2005. Estimating wave tolerance of Spartina alterniflora in coastal Alabama. Journal of Coastal Research, 21(3), 453-463.

Schretlen, J.L.M. and J.J. Van der Werf. 2006. SANTOSS Database: Existing data from experiments in oscillatory flow tunnels and large wave flumes, University of Twente, Enschede, The Netherlands.

SonTek. 1997. Pulse coherent Doppler processing and the ADV correlation coefficient, SonTek, San Diego.

Struve, J., R.A. Falconer and Y. Wu. 2003. Influence of model mangrove trees on the hydrodynamics in a flume. Estuarine Coastal and Shelf Science, 58(1), 163-171.

Teh, S.Y., H.L. Koh, P.L.F. Liu, A.I.M. Ismail and H.L. Lee. 2009. Analytical and numerical simulation of tsunami mitigation by mangroves in Penang, Malaysia. Journal of Asian Earth Sciences, 36(1), 38-46.

Temmerman, S., T.J. Bouma, G. Govers, Z.B. Wang, M.B. De Vries and P.M.J. Herman. 2005. Impact of vegetation on flow routing and sedimentation patterns: Three-dimensional modeling for a tidal marsh. Journal of Geophysical Research-Earth Surface, 110(F4), 18.

Terray, E.A., B.H. Brumley and B. Strong. 1999. Measuring waves and currents with an upwardlooking ADCP. IEEE Sixth Working Conference on Current Measurement, San Diego, pp.

Van der Wal, D., A. Wielemaker-Van den Dool and P.M.J. Herman. 2008. Spatial patterns, rates and mechanisms of saltmarsh cycles (Westerschelde, The Netherlands). Estuarine Coastal and Shelf Science, 76(2), 357-368.

Van Rijn, L.C. 2008. Principles of fluid flow and surface waves in rivers, estuaries, seas and oceans. Aqua Publications, The Netherlands.

Vo-Luong, P. and S. Massel. 2008. Energy dissipation in non-uniform mangrove forests of arbitrary depth. Journal of Marine Systems, 74(1-2), 603-622.

Wolanski, E., S. Spagnol and E.B. Lim. 2002. Fine sediment dynamics in the mangrove-fringed, muddy coastal zone. In: T.R. Healy, Y. Wang and J.-A. Healy (Editors), Muddy coasts of the world: processes, deposits and function. Proceedings in Marine Science. Elsevier Science B.V., pp. 279-292.

Yang, S.L. 1998. The role of Scirpus marsh in attenuation of hydrodynamics and retention of fine sediment in the Yangtze Estuary. Estuarine Coastal and Shelf Science, 47(2), 227-233. 